\title{
Para uma biografia da pequena propriedade rural no oeste catarinense
}

\author{
For a biography of small rural property in western Santa Catarina
}

Para una biografía de la pequeña propiedad rural en el oeste catarinense

\section{Resumo}

Este texto é uma tentativa de traçar uma biografia da pequena propriedade rural no oeste catarinense. Esta surge nas franjas das fazendas e nas áreas florestais dos Campos de Palmas. Após a Guerra do Contestado, dezenas de empresas colonizadoras instalam-se na região para vender pequenas glebas aos agricultores oriundos do Rio Grande do Sul. Essa pequena propriedade, tal como um personagem, em período de emancipação, expande-se pelo território, ocupando as áreas florestais, desencadeando conflitos com povos indígenas e autóctones para firmar-se como o modelo de colonização. As lutas pela cidadania conduzem os proprietários ao engajamento em movimentos sociais e à conquista de terras. No momento de maturidade, são enfrentados crises e desafios do mode-

Arlene Renk ${ }^{*}$

Silvana Winckler*

\footnotetext{
Doutora em Antropologia, vinculada ao Programa de Pós-Graduação em Ciências Ambientais e em Direito da Unochapecó. E-mail: arlene@unochapecó.edu.br

** Doutora em Direito, vinculada ao Programa de Pós-Graduação de Ciências Ambientais e em Direito da Unochapecó. Pesquisadora vinculada ao Projeto Bases Históricas dos Conflitos Agrários Contemporâneos no Norte do Rio Grande do Sul e Oeste de Santa Catarina: indígenas, quilombolas e pequenos agricultores - memórias brasileiras conflitos sociais. E-mail: silvanaw@unochapeco.edu.br
}

Recebido em 10/03/2017 - Aprovado em 30/04/2017 http://dx.doi.org/10.5335/hdtv.17n.2.7496 


\section{Introdução}

Estatística e socialmente, o oeste catarinense ${ }^{1}$ é reconhecido como território constituído de pequenas propriedades rurais. Enquanto tal, essa é uma construção relativamente recente. Pretendemos descortinar o seu processo de constituição e o caráter irenista, observando os conflitos que emergem desse espaço.

Abreviadamente, o território no qual se insere a pequena propriedade em questão, em termos administrativos, teve início na Província de São Paulo, de 1839 até 1853. Destas datas até 1917, ele esteve vinculado ao Paraná e, a partir disso, foi incorporado a Santa Catarina, sem contar a contenda dos limites entre Brasil e Argentina, dirimidos em 1895, e aqueles do Paraná e Santa Catarina, solucionados após a Guerra do Contestado, momento no qual passou à administração catarinense. Um olhar retrospectivo permite obter indicativos de leitura situacional e de oposição ao lugar da pequena propriedade. Inicialmente, este esteve nas franjas dos grandes domínios, expressas nos "alqueires de capoeira", como será visto adiante. Pouco se sabe a respeito. Recebeu obsequiosos silêncios da historiografia. Na República Velha e no período getulista, inicia-se a constituição de campesinato de descendentes de europeus a custas daquele já estabelecido. Consolidada a pequena propriedade, fechada a fronteira agrícola, inviabilizada a reprodução social camponesa nos moldes anteriores, isto é, da migração dos deserdados, desencadeou-se o movimento dos trabalhadores rurais sem-terra, as ocupações de terra, os assentamentos de reforma agrária e a implantação de projetos neodesenvolvimentistas.

Se essa foi a démarche geral, cabe, então, esmiuçá-la para a construção da biografia da pequena propriedade. Se trazemos o aspecto legal não é por reiterar a história oficial, mas para tomar dela os marcos da dominação e de como silenciou e instituiu os processos de constituição dos campesinatos nesse período de aproximadamente dois séculos.

Para estudar esses conflitos, tomemos-lhes como eventos, como assinalado por Marshall Sahlins (1987), percorrendo o caminho da constituição da pequena propriedade, com o intento de traçar sua biografia, a exemplo do estudado por Kopytoff (2008); retemos deste autor os elementos que poderão subsidiar o nosso estudo. Kopytoff, etnografando contextos africanos, entendeu como pertinente traçar a biografia cultural das "coisas", a exemplo do que ocorre com as biografias de pessoas:

Parece-me que é vantajoso fazer a mesma variedade e modalidade de perguntas culturais para desvendar as biografias das coisas (KOPYTOFF, 2008, p. 92).

O percurso, ao tratar a pequena propriedade rural como "coisa", consiste em abordar a sua constituição, para entendê-la no que hoje é o oeste catarinense e o sentimento de mal-estar no mundo (BOURDIEU, 2012). Se a definimos como coisa, é no sentido de materialidade, o que não significa que seja desapegada de valores simbólicos. Compreende-se, aqui, a trajetória da constituição legal da propriedade, das relações da economia substantiva com a mercantilização mais acentuada por conta da economia formal, embora carregue ele- 
mentos de troca e reciprocidade na vida das colônias. Ressaltamos, também, que se trata de um trabalho embrionário, que receberá, oportunamente, aprofundamento, paralelo ao estudo da região.

Em termos de delimitação, para este texto, tomamos tão somente o que a literatura clássica considerou como campesinato. Ressaltamos que tratar da pequena propriedade é abordar o campesinato que, em última instância, independente de vertente teórica, carrega como marcas o trabalho familiar, a relação com a terra e a relação de subordinação com a sociedade circundante (SHANIN, 1971; GALESKI, 1972; SEYFERTH, 1974) - não incluímos, no entanto, os povos indígenas. Há literatura acerca dos povos ancestrais que ocuparam o território, como é evidente em estudos de Carbonera e Schmitz (2011). No que diz respeito aos povos indígenas, temos claro também que não os situamos no polo do passado, mas são merecedores de estudo, cujo intento não se insere neste momento. Quando abordados, é em relação aos proprietários de terra ou aos pequenos agricultores.

Os conflitos agrários envolvendo as pequenas propriedades do oeste catarinense não nascem como deus ex-machina e tampouco são frutos de uma história evolucionista, mas se fazem presentes nos eventos (SAHLINS, 1987), além de construí-los.

$\mathrm{O}$ texto pretende problematizar o contexto histórico e social da formação dos principais conflitos no território ora nominado de oeste catarinense. Quais as possibilidades de construir a biografia da pequena propriedade e seu lugar nos conflitos agrários no oeste catarinense?

\section{Assim começa a biografia: no princípio eram os campos}

O que hoje constitui o oeste catarinense, no século retrasado, era parte dos chamados Campos de Palmas, encravados entre os rios Iguaçu e Uruguai e cercados pelo sertão nacional. Precede esses campos os de Guarapuava, conquistados sob o beneplácito da Carta Régia de 1809, que previa: “Approva o plano de povoar os Campos de Guarapuava e de civilisar os indios barbaros que infestam aquelle território" (BRASIL, 1809). Em 1839 , os campos de Guarapuava foram considerados povoados, e fração dos fazendeiros ou descendentes deles se deslocaram ao sul, aos campos de Palmas, em zona de ocupação e fronteiras estratégicas para o governo brasileiro, diante dos litígios a oeste, com a Argentina. Era um povoamento de área de campos com atividade de pecuária, deixando de lado as áreas florestais. Nessa ocupação, estabeleceu-se o caminho das tropas, a Estrada das Missões, que fazia o percurso do Rio Grande do Sul aos Campos Gerais, com pequenos povoados.

O apossamento desses campos foi conflituoso com os índios coroados (Kaingang) que ali habitavam. Os conquistadores estabeleceram um processo de aliança com uma fração indígena, chamada de "mansa", e repeliram a outra, nominada de "arredia", numa guerra fratricida (SANTOS, 1974, 1978). Tratou-se de uma apropriação privada de campos, esbulhando-os do povo Kaingang, estabelecendo campos de criar em grande propriedade. A prevalência dessa grande propriedade não significou a ausência das pequenas, com o excedente da 
população dos campos e de extratores de erva-mate, em busca de espaço, estabelecidos, em geral, nas franjas das fazendas e nas áreas de mata, considerando que significava ser o sertão nacional. Além da perda das terras, os indígenas foram "chamados à catequese ou à civilização", o que representou o ônus do etnocídio aos nativos, com marcas de estigma na sociedade regional.

A Lei $n^{\circ} 601 / 1850$ pode ser considerada o evento por excelência nas questões fundiárias do Brasil. Ao proibir-se a ocupação de terras por posse, a compra passa a ser o único meio de acesso ao mercado fundiário. A legislação previa as formas de regularização das terras e mantinha abertas as portas para a colonização com "colonos importados" e com propagandistas na Europa para o recrutamento. Os imigrantes europeus brancos passam a ser os preferidos no processo de imigração para colonização, em pequena propriedade, em detrimento aos nacionais. Seyferth assegura que o "discurso imigrantista oficial fica evidente com a política de colonização [que] tinha o propósito de povoar terras devolutas com 'gente civilizada', de raça 'branca'” (2011, p. 406). E não obstante o interesse mais amplo da imigração europeia, a legislação estabeleceu a sinonímia entre colono e imigrante, tendo em vista a primazia dada ao estabelecimento de núcleos coloniais.

Há de se considerar, ainda, que muitos dos nacionais, moradores de lotes considerados então como devolutos, não tinham existência civil. Indocumentados, não contavam para as estatísticas, fato que contribuiu para a posterior expropriação. Ressalte-se que o modelo da pequena propriedade é explicitado, nessa lei, como o antônimo da grande propriedade.

$O$ fato de a Lei de Terras (Lei $n^{\circ}$ 601/1850) ter oferecido oportunidades de legalização aos posseiros das pequenas frações não significa que a maioria tenha atendido às suas exigências. Algumas hipóteses podem ser aventadas. Ou os posseiros não eram conhecedores da lei, ou, motivados pela concepção de terra como um bem fora do mercado, considerável fração não entendeu como necessário atendê-la, o que acarretou, mais tarde, o processo de expropriação. De qualquer forma, o registro da terra tratava-se de algo novo, inusitado, frente ao que se fazia até então.

Os registros de terra, na capela de Palmas, em cumprimento ao Decreto $\mathrm{n}^{\mathrm{o}} 1.318 / 1854$, que regularizou a Lei de Terras, apontam, embora com parcimônia, os requerimentos de áreas pequenas, comparadas aos campos. Neste caso, o pequeno é tomado relacionalmente às áreas de campo referidas em termos de léguas (RENK, 2006). As pequenas áreas, mesmo que em reduzido número, nos Campos de Palmas, são referidas em termos de alqueires de capoeira:

[...] consistem de 'terrenos de plantação', 'capoeira de planta de milho', 'alqueires de planta de milho', 'terras de lavoura', 'terras lavradias', 'terras de cultura', 'capoeiras, matos e catanduvas'. Além disso, há evidências de isolamento, pelas confinações apresentadas, isto quando o ocupando afirma conhecê-las. Não raro encontram-se áreas, principalmente as de cultura, que confinam 'por todos os lados com o sertão nacional' ou com 'terrenos nacionais', ou onde um dos limites seja o 'sertão nacional' (RENK, 2006, p. 46). 
Cabe retornar ao Decreto ${ }^{\circ} 1.318 / 1854$, que regulamenta a execução da Lei de Terras. O Capítulo VII trata:

Das terras devolutas situadas nos limites do Imperio com Paizes estrangeiros. Prevê a instalação de colônias militares. Lotes a serem cedidos gratuitamente aos colonos e a outros povoadores nacionais ou estrangeiros (BRASIL, 1854).

Esses são marcos para a ocupação do espaço. As colônias militares, previstas em 1854, só serão fundadas em 1882. Uma delas, a do Chapecó, foi detalhada no Decreto $\mathrm{n}^{\circ} 2.502 / 1859$, assegurando que as colônias previstas visavam à proteção dos habitantes dos Campos de Palmas, Erê, Xagu e Guarapuava, "contra a incursão dos índios, e a chamar os ditos índios, com auxílio da catechese à civilização" (artigo $2^{\circ}$ ) (BRASIL, 1859).

Na abrangência dos Campos de Palmas, foram criadas duas colônias militares, a de Chopim e a do Chapecó - esta, nos limites do que seria o atual oeste catarinense. Pelo decreto, na ausência de praças, o Comandante poderia recrutar colonos para a função. Os colonos militares seriam compensados com data de terra, edificação da moradia e data de terra para cultura ou criação, nunca excedendo a um quarto de légua quadrada para cultura e uma légua quadrada para criação. Além disso, abria-se a possibilidade de conceder lotes de criar e de cultivo, nas medidas mencionadas, para brasileiros não colonos, desde que cumprissem o requisito de morar na área. Não cumprida em um ano, tornar-se-ia caduca a concessão.

Pinheiro Machado (2007) retrata com muita propriedade que as colônias militares formadas estavam situadas nas fronteiras, em áreas de desinteresse das companhias colonizadoras que importavam os colonos estrangeiros, ligadas ao Ministério da Agricultura. No caso da Colônia do Chapecó, criada em 1882, o Capitão Bormann, comandante da colônia, encontrara famílias ocupando "indevidamente" áreas de terra entre a colônia traçada e o Goio-En, convidando-os a fazer parte da colônia, no que fora atendido por 40 famílias que foram estabelecer-se em dispêndio de recursos públicos. Tratou-se de estratégia de recrutamento para adensamento da Colônia, que, além dos praças, poderia ter determinado número de agricultores. Embora fosse um campesinato, estava regulamentado sob a autoridade militar. Coelho dos Santos (1974, p. 108) informa que foram expedidos 255 títulos de terra da colônia militar. Posteriormente, quando esse território foi incorporado a Santa Catarina, o Decreto estadual $n^{\circ} 46$, de 1934, reconheceu a validade dos títulos distribuídos pela colônia militar (WERLANG, 2006, p. 32). Sobre os índios chamados à catequese, os fatos narrados é que ficavam fora do perímetro da vila da colônia.

A nossa biografada, seguramente, não estava centrada nas áreas de alqueires que, embora em número reduzido, não seriam exatamente a pequena propriedade instaurada no século seguinte, mas o era em relação aos campos de criar. Nossa biografada também não se sentiria contemplada com um quarto de légua ou uma légua de terras da colônia militar, embora fosse uma pequena propriedade em relação às léguas de campo. Supõe-se a constituição de um campesinato caboclo em áreas florestais, com pequenas 
roças, como são os relatos colhidos por descendentes décadas mais tarde (RENK, 2006; DEBONA, 2010; REICHERT, 2008; POLI, 2006), efetivamente com pequenas propriedades. Esse campesinato perdurará até as primeiras décadas do século XX. No caso em estudo, perdurarão a economia substantiva e as escassas relações de mercado. A concepção de terra dessa população contribuiu para sua perda. Os brasileiros ocupavam-na como bem entendiam. Algumas famílias exploravam os faxinais, respeitando a paisagem, sem destruir as matas para a criação de animais e mantendo as roças a certa distância, sem risco de serem ameaçadas pelos animais. O trabalho, principalmente com o gado, era coletivo. Outros preferiam uma vida mais itinerante, escolhiam um lugar adequado, bom de água, para morar e plantar, permaneciam por uma ou duas safras e, depois, seguiam adiante. A abundância de terras permitia deslocamentos e a escolha de novos lugares para moradia.

Efetivamente, a terra não era um bem raro, na acepção de Foster (1967), porque os habitantes dispunham de áreas e de baixa concorrência, podendo mudar-se, se fosse o caso. A terra era de Deus ou do Brasil, e não havia por que comprá-la. Ela não existia enquanto mercadoria. Nesse sentido, encontramos respaldo em Karl Polanyi (1980), ao estudar sociedades chamadas arcaicas, nas quais a terra não consistia em mercadoria, e os embates entre valores e práticas das sociedades arcaicas com os da sociedade de economia de mercado autorregulável. A economia de mercado é apenas uma delas:
Uma economia de mercado deve compreender todos os componentes da indústria, incluindo o trabalho, terra e dinheiro. [...] Acontece, porém, que o trabalho e a terra nada mais são do que os próprios seres humanos nos quais consistem todas as sociedades, e o ambiente natural no qual elas existem. Incluí-los no mecanismo de mercado significa subordinar a substância da própria sociedade às leis de mercado. [...] O ponto crucial é o seguinte: trabalho, terra e dinheiro são elementos essenciais da indústria. Eles também têm que ser organizados em mercados e, de fato, esses mercados formam uma parte absolutamente vital do sistema econômico. Todavia, o trabalho, a terra e o dinheiro obviamente não são mercadorias. O postulado de que tudo o que é comprado e vendido tem que ser produzido para a venda é enfaticamente irreal no que diz respeito a eles. Em outras palavras, de acordo com a definição empírica de uma mercadoria, eles não são mercadorias. Trabalho é apenas um outro nome para a atividade humana que acompanha a própria vida que, por sua vez, não é produzida para venda mas por razões da vida, não pode ser armazenada ou mobilizada. Terra é apenas outro nome para a natureza, que é produzida pelo homem. [...] A descrição do trabalho, da terra e do dinheiro como mercadorias é inteiramente fictícia (POLANYI, 1980, p. 83-86, grifo do autor).

Na mesma conjuntura histórica em que a grande propriedade caminhou do apossamento dos campos para a mercantilização, como se pode depreender de documentos do inventário de Anna Maria Jesus, cujo inventariante foi Jose Raymundo Fortes, no Ofício de Órfãos em Palmas (FORTES, 1990, p. 69-71), com discriminação de bens móveis, imóveis e dívidas, a pequena propriedade esteve à margem, incrustada num 
processo de economia autossustentável, no qual a terra ainda não é mercadoria.

\section{Pós-Guerra do Contestado e fim das terras de plantar e de criar}

Um grande evento do pós-Contestado foi o Acordo dos Limites de 1917, firmado entre os governos do Paraná e de Santa Catarina, à medida que implicava a revalidação das titulações de terras feitas pelo Paraná. Dentre essas áreas, situava-se as da Brazil Development, subsidiária da Brazil Raywail, em razão do contrato firmado no Império, que concedia $15 \mathrm{~km}$ de terras ao longo da ferrovia, como contrapartida por sua construção (VINHAS DE QUEIROZ, 1981). Para Wachowicz (1984), o governo do Paraná, cumprindo as cláusulas do contrato, deslocava as glebas de terra ao interior da área contestada, que passaria ao domínio catarinense. Na revalidação das terras, a partir de 1917, a Brazil Development obrigava-se a demarcar os lotes em áreas de 20 a 25 hectares, para áreas de cultivo, e de 100 a 1.000 hectares, para indústria extrativa e pastoril, bem como a construir estradas de rodagem que comunicassem todos os lotes (PIAZZA, 1983, p. 536). Essa empresa delegou glebas de terra a outras colonizadoras, considerando haver cláusula contratual com o Estado catarinense de comprometimento à colonização até 1932.

O que ocorre, então, é a transferência de glebas retalhadas em minifúndios em todo o interior do oeste catarinense, num grande projeto de colonização, sob responsabilidade de dezenas de empresas sul-rio-grandenses. Ocorre, igualmente, a transferência das terras do campesinato parcelar caboclo para um campesinato étnico descendente de europeus, os chamados "de origem", ou seja, descendentes de alemães, italianos e poloneses, que migram numa estratégia de reprodução social camponesa. Da mesma maneira, no vínculo com a empresa colonizadora, a relação de aquisição da terra passa pelos crivos da mercantilização e da monetarização.

Esse é o momento da etnicização, resultando na etnogênese dos caboclos (BANTON, 1979), ocasião em que foram transformados em minoria social, uma vez desestruturada a base morfológica, o que favoreceu a expropriação desse campesinato. Trata-se de um evento de intersecção de dois campesinatos, um em sua constituição e consolidação enquanto modelo de pequena propriedade e outro na desqualificação de seu modelo e de seu modo de vida.

As pequenas posses dos caboclos, em vários pontos do território, passam a ser nominadas como posses "indevidas", cujas terras, em grande maioria, serão reivindicadas como devolutas. Esses aspectos serão retomados adiante. Por ora, até o final da Guerra do Contestado, não há maiores indícios de conflitos entre a roça cabocla e os proprietários das léguas de campo, considerando-se a baixa concorrência do mercado imobiliário.

\section{0 evento colonial}

O fim da Guerra do Contestado levará às medidas de ocupação do território, fazendo com que o governo catarinense estimule e impulsione a inserção das companhias colonizadoras para venda de lotes, em pequena propriedade, a chamada colônia, ${ }^{2}$ aos 
colonos de origem, isto é, descendentes de alemães, italianos e poloneses, do estado do Rio Grande do Sul.

O empenho do Estado catarinense em colonizar a região pode ser observado num evento nominado como Bandeira de Konder, ${ }^{3}$ no qual são pródigas as formas de representações a respeito da região e do povoador desejado. Em primeiro lugar, considera-se essa região como um "deserto", ou melhor, "deserto do norte", a ser povoado pelos colonos do sul, que o transformariam num "Éden", numa "Canaã". Noutro momento, é considerada como "terras ubérrimas do Nilo" (BOITEUX, 1931, p. 8). Os colonos migrantes são vistos como "os obreiros da civilização" (COSTA, 1931, p. 21). Boiteux é enfático a respeito dos migrantes, colonos descendentes de alemães e italianos: "toda uma gente forte e decidida, disposta ao trabalho, levando aquelles rincões, até há pouco incultos por abandonados, a prosperidade e a riqueza" (1931, p. 10).

Cartograficamente, o desenho do mapa com as colonizadoras instaladas na região, nas primeiras décadas do século $\mathrm{XX}$, é de um retalhamento do território em linhas retas ou até encontrar o curso de água, que remete ao mapa colonial africano no pós-Primeira Guerra Mundial, quando de sua divisão pelas potências estrangeiras, definido por Balandier (1951) como situação colonial. O olhar microscópico apontará uma particularidade, o traçado das pequenas glebas, as chamadas colônias, era em forma de espinha de peixe, de modo que os lotes coloniais a serem vendidos aos agricultores tivessem acesso à água dos cursos de rios e à estrada, garantindo a comunicação. Essa tarefa ficou a cargo dos agrimensores das companhias colonizadoras.

Há um recrudescimento em relação aos posseiros. Após a revalidação de glebas da Brazil Development, no contrato com essa empresa, o governo catarinense envida esforço para "manter a ordem nos núcleos coloniais e zonas próximas, bem como desembaraçar as terras de pretensões infundadas de terceiros" (WERLANG, 2006, p. 33, grifo nosso).

Outras formas elementares de acusação são perceptíveis nos documentos, como o caso do Decreto $n^{\circ} 21 / 1925$, que considerava as invasões ou ocupações ilegais como posses criminosas, passíveis de despejo, ou seja, fechava-se o cerco às áreas caboclas. Se aos caboclos as ações do Estado iam em direção à criminalização, em relação às colonizadoras, iam em direção oposta. Generosamente, previa-se a troca de terras pela abertura de estradas e o arrendamento de terras para extração de erva-mate. A ampliação das revalidações pela abertura de estradas, aparentemente, era um negócio rentável. Um exemplo apresentado por Werlang (2006) consiste na abertura de um metro linear de estrada corresponder a $10.000 \mathrm{~m}^{2}$ de área colonizável, o que ampliaria consideravelmente o acervo das colonizadoras que se propunham a realizar esse feito.

Outra estratégia de cerceamento e vigilância aos caboclos foi o arrendamento de extensas áreas de terra pelo Estado a empresários, para a extração da erva-mate, com promessa de futuro loteamento.

A instalação de dezenas de colonizadoras, disputando entre si os colonos do Rio Grande do Sul, não deixou de despertar con- 
flitos entre essas companhias, principalmente as contestações encetadas pela Brazil Raiwayl, que alegava ser proprietária das áreas, como foi o caso da Companhia Territorial Sul Brasil e da Empresa Oeste Colonizadora, com disputas da oligarquia catarinense. $\mathrm{O}$ último caso resultou em ataques difamatórios mútuos na imprensa e nos núcleos coloniais (WERLANG, 2006, p. 41).

$\mathrm{O}$ deslocamento desse contingente foi essencialmente por razão interna ao campesinato, sua reprodução social. As condições de aquisição de lotes nas áreas florestais eram mais favoráveis que no Rio Grande do Sul. Deslocar-se até a "serra" (como nominavam os agricultores descendentes de alemães) era um imperativo para continuar na condição de pequeno agricultor. O que se observa, aqui, é que o contingente migrante trará uma concepção mais mercantilizada da propriedade, embora não possa dizer que a terra seja sempre mercadoria estrito senso. Seguramente, na hora de firmar contrato com a companhia colonizadora, haveria a conotação da mercantilização. Poderia ser o lote A ou B, na gleba X ou Y, seria mercadoria, no entanto, uma mercadoria revestida de caráter moral e eivada de aspectos porosos de economia substantiva. Do ponto de vista do Estado catarinense, a escolha pelo povoador das novas colônias recaiu no migrante descendente de europeu vindo do Rio Grande do Sul, como foi apontado. Foram acionados os estereótipos daquele sujeito da imigração, ou seja, branco, descendente de europeu, com ethos de agricultor.

Estabelecem-se dezenas, se não centenas, de colônias novas, no período após o Contestado, para a pequena propriedade, com povoador de perfil e habitus desejado. Os conflitos interpostos consistem no desalojamento de um campesinato para a substituição por outro. Quais os elementos que entraram em jogo? Subjetivamente, podemos mencionar o conflito de habitus (concepção de terra, futuro, posse, acúmulo) entre colonos e caboclos, a expropriação da terra pelas colonizadoras, com a limpeza das áreas, fim do modo de vida dos faxinais, implantação de uso intensivo do solo pelos agricultores, predominância de um modelo de agricultura: pequena propriedade. Como mencionamos, tratou-se de um processo de etnogênese, que resultou em friç̧ão interétnica dos dois grupos, isto é, daqueles estabelecidos, os caboclos, e daqueles migrantes.

Em tese, as companhias colonizadoras tiveram a responsabilidade de retirada dos posseiros, que passaram a ser nominados por intrusos, fazendo a limpeza das terras. Em parte, houve o uso de força policial, de força das próprias companhias e de outros subterfúgios que não serão nunca explicitados. Muitos se engajaram nas atividades extrativas da erva-mate ou das madeireiras, outros foram ao "Paranã", local não concorrido pelas colonizadoras. Extraviando-se dos troncos velhos, isto é, dos ancestrais, outra parte se estabeleceu nas áreas declivosas e em beira de rios não concorridas naquele momento.

As companhias colonizadoras, a exemplo de Luce \& Rosa, Sul Brasil, Volksverein, dentre outras, trabalharam para que houvesse núcleos coloniais homogêneos do ponto de vista étnico e confessional. Assim, Porto Feliz (atual Mondaí, Palmitos e Nova Teutônia) foi destinado aos colonos alemães e seus descendentes de confissão luterana. Já Porto 
Novo (atual Itapiranga) e São Carlos foram destinados exclusivamente a alemães e descendentes católicos. Nova Milano (Seara) e São Domingos (Caibi) eram núcleos criados para descendentes de italianos e católicos. Alguns núcleos eram mistos do ponto de vista confessional, mas respeitavam espaços para cada um dos credos predominantes, tais como o cemitério e a construção de igreja, outros, no entanto, eram homogêneos do ponto de vista étnico e confessional, isto é, católicos e descendentes de italianos, considerando que estes representaram a maioria do fluxo migratório. Não há registros de companhias que tenham destinado lotes ou frações de glebas para colonização de caboclos; ao contrário, dificultavam-lhes o eventual interesse de compra.

O modelo idealizado estabeleceu-se, o que não significa que sua leitura partilhe dos ideólogos da colonização. Se vieram para colonizar o "deserto do norte", seguramente, os contratempos e as adversidades exigiram ascetismo e rigorismo dos tempos iniciais, das virtudes étnicas, das privações, da necessidade feito virtude (BOURDIEU, 1979), de "viver como negros" (RENK, 2000, p. 168). As narrativas são eivadas de ressentimentos pelo esforço investido na propriedade, pelo isolamento e pela falta de recursos, principalmente daqueles da área médica.

Considerando que a pequena propriedade representou um relativo preenchimento das vendas das colonizadoras, isso se deve ao fato de que ela representou uma estratégia de reprodução social camponesa. A aquisição de terra em glebas florestais a preço mais módico que no Rio Grande do Sul possibilitava a compra de uma colônia e, eventualmente, até de duas ou mais, conforme o grau de capitalização da família. No entanto, nem todos dispunham desse montante, adquirindo apenas meia colônia. Quando o ciclo de vida familiar se apresentava com filhos em idade de constituir suas próprias famílias, havia possibilidade de aquisição de novas áreas. Aqueles de menor capitalização fracionavam a colônia. Entretanto, o modelo idealizado, o da pequena propriedade, apresentava falácias, ao garantir a reprodução social de toda a prole na mesma condição. No entanto, é no interior da propriedade que se encontra o maior conflito: a diferença de gêneros e o deserdamento das mulheres. Se a propriedade paterna pode ser considerada patrimônio moral e é destinada ao herdeiro, geralmente, o ultimogênito, que se responsabilizará pelo cuidado dos pais, os demais integrantes masculinos são compensados com terra ou outros bens, o que traz implícita a carga da mercantilização. Isto é, a mercantilização pode ser abstraída da propriedade paterna, mas se faz presente nas demais. A clivagem de gênero, compensando as mulheres com enxoval, máquina de costura e novilha, isto é, aos capitalizados, representou uma teratologia, avaliada a posteriori pelas parcelas excluídas.

\section{E ela quer se tornar cidadã}

A continuação abordará o fechamento de fronteira agrícola, o que tem gerado conflitos internos e externos e a mobilização de movimentos sociais, os quais se constituem como constelação, na conquista de direitos. Ora são acionados pela luta por preços justos, ora pela reivindicação dos direitos po- 
líticos e sociais. Ora rebatem sob a pequena propriedade as lutas dos povos indígenas, reivindicando as terras usurpadas no processo de colonização, o que sempre tem sido evento doloroso, pelas lógicas diferenciadas dos dois grupos, ora se deparam com os grandes projetos, como hidrelétricas construídas e em construção, que, não obstante seus embates, estão mais para a lógica da inevitabilidade que da pequena propriedade. E por que não falar das alterações do substrato desse campesinato, das migrações, da recusa da condição camponesa, do celibato no campo?

\section{Abstract}

The text is an attempt to draw a social biography of the small rural property in the west of Santa Catarina. It is present in the fringes of the farms and in the forest areas of Palmas Fields. In the post Contestado War period, dozens of colonizer companies settle in the region with the intent of selling small pieces of land to peasants from Rio Grande do Sul. The character, in a period of emancipation, expands into the regional territory occupying the forest areas, triggering conflicts with indigenous peoples and natives to establish itself as a model of colonization. The struggles for citizenship led it to the engagement of social movements and land conquests. At the time of character's maturity, it faces crises and challenges of the neo-development model, which with great projects, affects the model of small property.

Keywords: Agrarian model. Colonization. Family farming.

\section{Resumen}

El texto es un intento de trazar una biografía de la pequeña propiedad rural en el oeste catarinense. Esta surge en las franjas de las haciendas y en las áreas forestales de los Campos de Palmas. En los últimos años, la mayoría de las personas que viven con el VIH / Sida en el país, $\mathrm{Y}$ autóctonas para firmarse como el modelo de colonización. Las luchas por la ciudadanía lo llevan al compromiso en movimientos sociales ya la conquista de tierras. En el momento de madurez, se enfrenta a crisis y desafíos del modelo neodiversacional, con grandes proyectos que rebote en el interior de ese modelo de estructura agraria.

Palabras claves: Agricultura familiar. Colonización. Modelo agrario.

\section{Notas}

1 Para delimitação do presente trabalho, tomamos como oeste catarinense o território compreendido pelo município de Chapecó, criado em 1917, com a área de $14.000 \mathrm{~km}^{2}$, que, atualmente, abrangeria, a leste, a área entre os municípios de Vargeão, Abelardo Luz até a fronteira com a Argentina. Não desconhecemos as "lutas" de classificações para constituições de uma região (BOURDIEU, 1989) e tampouco as tipologizações oficiais adotadas pelo Instituto Brasileiro de Geografia e Estatística. Esse arbitrário foi nosso recorte.

2 Para Seyferth, a colônia, "Tomada em seu sentido particular, é a base da existência do camponês na área: inclui a propriedade com tudo o que ela contém (casa, estábulo, pastagem, roças, etc.). É, pois, a unidade básica dentro do sistema econômico em questão. No seu sentido mais geral, a colônia era o conjunto das pequenas propriedades que formam a área de colonização" (1974, p. 152). A categoria colono, como bem afirma Seyferth (2011, p. 410), foi apropriada do discurso oficial e usada para distinguir imigrantes e descendentes de outras categorias rurais. Foi empregada 
pelas autoridades para designar os imigrantes estabelecidos em núcleos coloniais, com o tempo, tornou-se a categoria básica da identidade social camponesa, com forte componente étnico.

3 Trata-se de viagem do presidente do Estado catarinense, em 1929, "tomando" posse da região, que resultou em três livros de registro de viagem de um álbum fotográfico, como prova documental dos feitos do deslocamento.

\section{Referências}

BALANDIER, George. La situation coloniale: approche théorique. Cahiers Internationaux de Sociologie, Paris, PUF, v. 11, p. 87-103, 1951.

BANTON, Michael. A idéia de raça. Lisboa: Edições 70, 1979.

BOITEUX, José. Oeste Catharinense: de Florianópolis a Dionisio Cerqueira. Florianópolis: Alberto Entres, 1931.

BOURDIEU, Pierre. La Distinction: critique sociale du jugement. Paris: Minuit, 1979.

2012. . A miséria do mundo. Petrópolis: Vozes, . O poder simbólico. Rio de Janeiro: Bertrand Brasil, 1989.

BRASIL. Carta Regia, de 01 de abril de 1809. Disponível em: <http://www2.camara.leg. br/legin/fed/carreg_sn/anterioresa1824/ cartaregia-40045-1-abril-1809-571613-publicacaooriginal-94759-pe.html>. Acesso em: 10 jun. 2017.

BRASIL. Lei $\mathrm{n}^{\circ}$ 601/1850. Disponível em: <http://www2.camara.leg.br/legin/fed/ carreg_sn/anterioresa1824/cartaregia-40045-1-abril-1809-571613-publicacaooriginal-94759-pe.html>. Acesso em: 05 jun. 2017.

BRASIL. Decreto $n^{\circ} 1.318 / 1854$. Disponível em: <http://www.planalto.gov.br/ccivil_03/ decreto/1851-1899/D1318.htm>. Acesso em: 05 jun. 2017.

BRASIL Decreto n ${ }^{\circ}$ 2.502/1859. Disponível em: $<$ http:/ /legis.senado.gov.br/legislacao/Deta-
lhaDocumento.action?id=82690>. Acesso em: 05 jun. 2017.

CARBONERA, Mirian; SCHMITZ, Pedro Ignacio (Org.). Antes do oeste catarinense: arqueologia dos povos indígenas. Chapecó: Argos, 2011.

COSTA, Arthur Ferreira. O Oeste Catharinense: visões e sugestões de um excursionista. Rio de Janeiro: Villas Boas e Cia., 1931.

DEBONA, Narcelio Inacio. O caboclo de Palma Sola e arredores: depoimentos das décadas de 1930-1960. Dissertação (Mestrado em História) - Universidade Federal do Paraná, Curitiba, 2010.

FOSTER, George. Peasant society and the image of limited goods. In: POTTER, J. et al. Peasant society: a reader. Boston: Little Brown, 1967. p. 293-315.

GALESKI, Boguslaw. Basic concepf of Rural Sociology. Manchester: Manchester University Press, 1972.

KOPYTOFF, Igor. A biografia cultural das coisas: a mercantilização como processo. In: APPADURAI, Arjun. A vida social das coisas: as mercadorias sob uma perspectiva cultural. Niterói: Editora da Universidade Federal Fluminense, 2008. p. 89-121.

PIAZZA, Walter. Santa Catarina: sua história. Florianópolis: Lunardeli, 1983.

PINHEIRO MACHADO, Paulo. O sertão de Palmas: fronteira agro-pastoril e conflitos sociais. In: CONGRESSO LATINO AMERICANO DE HISTORIA ECONÓMICA, 1, 2007, Montevideo. Anales... Montevideo: International Economic History Association Republica, 2007. v. 1. p. 53-68.

POLANYI, Karl. A grande transformação: as origens de nossa época. Rio de Janeiro: Campus, 1980.

POLI, Jaci. Caboclo: Pioneirismo e Marginalização. Cadernos do CEOM, Chapecó, a. 19, n. 23, p. 149-187, 2006. 
REICHERT, Patrício. Diferenças culturais entre caboclos e teuto-brasileiros de Porto Novo: a segregação social do caboclo. Dissertação (Mestrado em História) - Universidade Federal do Rio Grande do Sul, Porto Alegre, 2008.

RENK, Arlene. Sociodiceia às avessas. Chapecó: Grifos, 2000.

A luta da erva: um ofício étnico da nação brasileira no oeste catarinense. Chapecó: Argos, 2006.

SAHLINS, Marshall. Ilhas de História. Rio de Janeiro: Jorge Zahar, 1987.

SEYFERTH, Giralda. A colonização alemã no vale do Itajaí Mirim: um estudo do desenvolvimento econômico. Porto Alegre: Movimento, 1974.

. Campesinato e Estado no Brasil. Mana, Rio de Janeiro, v. 17, n. 2, p. 395-419, 2011.

SHANIN, Teodor. The awkward class. Oxford: Clarendon Press, 1971.

VINHAS DE QUEIROZ, Maurício. Messianismo e conflito social: a guerra sertaneja do contestado: 1912-1916. São Paulo: Ática, 1981.

WACHOWICZ, Ruy. Paraná, sudoeste: ocupação e colonização. Curitiba: [s. n.], 1984.

WERLANG, Alceu. Disputas e ocupação do espaço no oeste catarinense: a atuação da Companhia Territorial Sul Brasil. Chapecó: Argos, 2006. 